\title{
TRANSFORMATIONAL DYNAMISM OF CIVIL SOCIETY ORGANIZATIONS
}

Open innovation, F(L)OSS, sharing economy, co-creation, social entrepreneurship, solidarity economy, platform cooperativism, peer production... These innovative patterns of broadening cooperation among civil society, market and public sector players can play important role also in emergence of knowledge society. The study analyses in this broader context the communities' transformational dynamism, which affects simultaneously the volunteers, their relationships, organization, and broader environment - provides the potential of social agency. This dynamism ensures also the capability to adapt by enabling to operate in rapidly changing environments. Multidimensional feedbacks and their aggregation into self-regulating loops create the civil society entities' responsiveness both inwards and outwards. Outward adaptivity can seem more spectacular; however, its inward dimension is at least as important. The adaptability feeds back also with the volunteers' self-reflection, which is of crucial importance to prevent the emergence and dominance of hierarchies. The study follows realist view of science and methodological pluralism - combines narrative description and case study driven generality focused concept creation. This constellation enables to identify components and transformational effects of the explored transformational dynamism by analysing a sample-case. In future studies the deployment of system dynamics can help to analyse also underlying processes unfolding in real domain.

Keywords: transformational dynamism, civil society organizations, cooperative relational dynamism, self-organizing, social agency.

$\mathrm{O}$ pen innovation, Living Laboratories, co-creation, co-design, free (libre) and open-source software (F(L)OSS), sharing economy, social entrepreneurship, solidarity economy, platform cooperativism, peer production... These innovative patterns facilitate to bring cooperation into competitive environments (Benkler, 2011) and catalyse broadening cooperation among civil society, market and public sector players what can play important role also in emergence of networked knowledge societies. This article elaborates in this broader context on sources and effects of the civil society organizations' transformational dynamism.

The research (Veress, 2016) explores a set of case-communities from Finland, the country, which became a poster child (eminent) and forerunner of EU-wide information and knowledge society related efforts starting from early years of the XXI Century. The Finnish innovation system consistently facilitated open and user driven innovation and catalysed the citizens' self-organizing participation in local and pan-European efforts. Acting as President of the Council of the EU Finland initiated and prepared in 2006 the official launching of the European Network of Living Laboratories foreseen as active catalysts of open innovation.

The original concepts of open innovation (Von Hippel, 1976, 1988, 2005; Chesbrough, 2003, 2006, 2009) emphasize the focal role of firms in combining innovative initiatives of external, often civil society related partners with non-traditional business models enabling successful marketization and company-level profit generation. However, large-scale patterns of cooperation like Wikipedia or free and open-source software communities (Raymond, 2001; Lee et al., 2003; Feller et al., 2005; Rifkin, 2004, 2011;
Hess - Ostrom, 2007) also provide sustainable patterns of value creation. Moreover, such networked peer production proved to be "not a bizarre side story of the Net, but a core vector through which the transition to a networked society and economy was happening"(Benkler, 2011: Acknowledgments). Recent tendencies similar to platform cooperativism and commons based peer production (CBPP) aim to facilitate the emergence of a cooperative counter-economy (Bauwens - Kostakis, 2017 a,b). There is also an ongoing "associational revolution" - as the first, decade-long, truly global Comparative Nonprofit Sector Project indicates. It brings about the "...rise of the civil society... (what) may, in fact, prove to be as significant a development of the late twentieth and early twenty-first centuries as the rise of the nation-state was of the late nineteenth and early twentieth centuries" - indicate Salamon et al. (2003, p. 2.). These feed backing trends often are mutually catalytic and constitutive of the emergence of a civil economy which "... is about how people live in communities"(Bruyn, 2000, p. 235.).

The literature indicates that despite these broad and feed backing transformational tendencies the civil society is (and remains) significantly under-researched (Anheier, 2004; Taylor, 2010). Moreover, “...one of the complexities of researching and discussing the activities of non-profits...is definitional. The research by DiMaggio and Anheier, while focussed on non-profits in the USA, speaks of 'balkanised literatures on specific industries and organizational data sets with neglected measures of legal form', replete with ideologically and culturally-loaded terminology (DiMaggio - Anheier 1990)..." - as Stillman (2006, p. 59.) recalls. However, the literature also indicates that volunteering participants of civil society organizations by 
capitalizing on self-communication (Castells, 2009) can exercise the Habermasian "dialogic democracy", where differences are settled, and practices ordered through discourse rather than violence or commands of authority - as Giddens (1984) points out. Such "democratisation of democracy" (Giddens, 1998) enhances and capitalizes on participative democracy. The volunteers during their recurrent everyday activities at their home, workplace or local community are capable of social agency by "going after the small picture" (Giddens, 1984, 1998) and through intense networking may generate broad transformations.

This paper aims to shed more light on sources and effects of the civil society organizations' transformational dynamism by considering as broader context the emergence of knowledge societies. A recurrent triangulation among (i) empirical data provided by iterative scrutiny of a Finnish case-community set, (ii) emerging (pre-) constructs, and (iii) relevant literature signalled about the usefulness:

- to follow scientific realist approach (Bhaskar, 1978),

- to consider process ontology and consequently process approach by deploying process narratives (Van de Ven - Poole, 2005),

- to follow methodological pluralism (Van de Ven Poole, 2005),

- to capitalize on qualitative research methods, primarily on case study-driven generality focused concept creation (Eisenhardt, 1989; Eisenhardt - Graebner, 2007; Tsoukas, 1989; Yin, 1981, 1994).

The realist approach (Table 1) enables to distinct and consider the interplay "....between (a) causal laws and empirical generalizations and (b) real structures, actual events, and experienced events" (Tsoukas, 1989, p. 559.). It allows comparing tendencies and events that a proposed construct forecasts with the observable events and phenomena by considering effects of 'concrete contingencies' (Tsoukas, 1989). In other words, it enables to increase the effectiveness of concept creation and improve internal validity and generalizability.

Table 1.

Extended ontological assumptions of realist view of science based on indications of Tsoukas (1989, p. 553.) with reference to Bhaskar (1978, p. 13.)

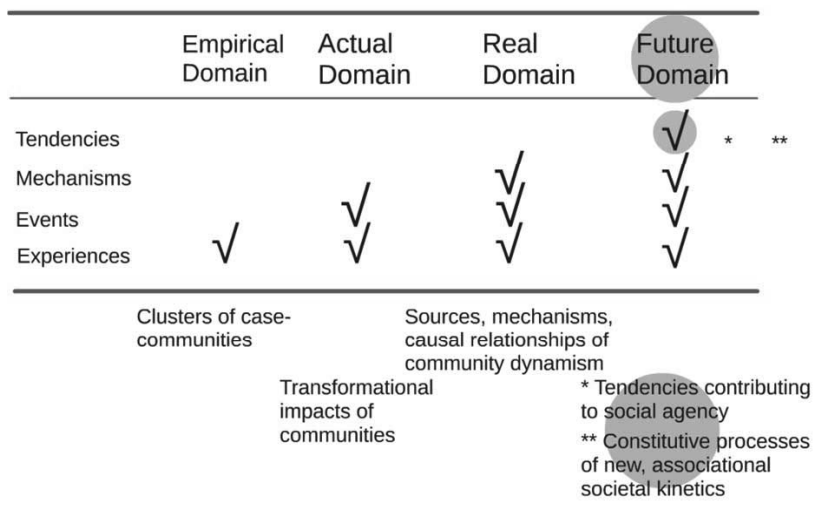

The implementation of process approach and ontology enables to overcome temptations to perceive causal relations as "unidirectional causal powers", which in epistemological context may seem to act "independently" even from interacting agents. To avoid such misperception the analysis should focus on causal relations that in ontological sense unfold as feedbacks among diverse processes consisting of personal interactions (their aggregating dyads). By following process approach one can deploy process narratives, i.e. "process studies of organizing by narrating emergent actions and activities by which collective endeavours unfold" (Van de Ven - Poole, 2005, p. 1387.). It enables to carry out "...narrative describing a sequence of events on how development and change unfold (Poole et al., 2000)..."(Van de Ven - Poole, 2005, p. 1380.).

The recursive triangulation indicated that a realist, contextual, process-oriented, explanatory and ideographic study of the civil society organizations' transformational dynamism can also capitalize on methodological pluralism (Van de Ven - Poole, 2005). It enables to analyse case-communities through combined deployment of process narratives and qualitative research methods, namely case study-driven concept creation (Eisenhardt, 1989; Eisenhardt - Graebner, 2007; Tsoukas, 1989; Yin, 1981, 1994; Van de Ven - Poole, 2005). Tsoukas (1989) argues for focusing on generality in order to improve the effectiveness of concept creation by going beyond examination of pattern replications inside and across cases. He offers practical ways and tools to consider the interplay among causal relations and contingent feedbacks through which these appear what also allows to "search evidence for 'why' behind relationships" (Eisenhardt, 1989, p. 533.). Such focus shift on generality enables to overcome mechanistic approach and rather follow a “...realist perspective (which) helps ...defining the generative mechanisms (causal powers)... and the kind of social structures that help sustain and reproduce these mechanisms ...(The) researchers do not postulate ironclad laws, but tendencies, which may or may not manifest themselves in the empirical domain... In this vein, paradoxical phenomena are not mere exceptions in stochastic conjunctions of events, or simple refutations of law-like generalizations, but rather the contingent link of a set of causal powers (italics in original)"(Tsoukas, 1989, p. 558.).

The combined deployment of process narratives and case-study driven generality focused concept creation as mutually complementary research methods facilitates to identify fundamental constituents of the civil society organizations' transformational dynamism. The narrative description of transformations observable in empirical domain facilitates to re-contextualize and reframe empirical data in the explored sample-case by indicating (pre-) constructs constitutive of community dynamism as well as to identify a set of related alterations in relational, organizational and various other dimensions The subsequent deployment of the generality focused concept creation (Tsoukas, 1989) facilitates the more in depth analysis of processes and real events unfolding in actual domain (Bhaskar, 1978; Tsoukas, 1989). It facilitates to identify 
emerging and feed backing constructs of the civil society organizations' transformational dynamism. The subsequent analysis of other case-communities belonging to the explored cluster enables to scrutinize, cross-check the presence, variations, or absence of these (pre-) constructs, and also to refine their characteristics and transformational effects. Consequently, the proposed pluralist approach, the combination of methodologies facilitates to increase the effectiveness, and improve both the validity and generalisability of construct creation. The research proposes as a next step to promote and fine tune concept creation, to analyse underlying causal relationships in real domain (Bhaskar, 1978; Tsoukas, 1989) by following pluralist approach - to be discussed in a separate paper.

\section{Neighbourhood Association - professional enabling of self-organizing}

The iterative processing of the research interviews enabled to identify 21 case-communities and group them into five clusters (Veress 20016). Their recurrent scrutiny by deploying combined research methods indicated that one of them can serve as sample-case. The Neighbourhood Association operating as umbrella organization of the local civil society in the Arabianranta district of Helsinki allowed identifying 'inflection points' in various feed backing change processes in multiple feed backing dimensions including (self-) communication, resourcing or self-empowerment.

The development of Arabianranta was perceived and planned (from the 90's) as large, decade-long pilot for complex district-wide programmes following thematic approach. The complex image of Arabianranta combined various components like art and design city, a high tech hub, and a XXI Century virtual village. The program also served as a model for knowledge society developments at local level and its important task was to strengthen the civil society. After 2006, when the Finnish EU presidency officially launched the Living Laboratories' pan-European network the district became also a Living Laboratory pilot for Helsinki and the metropolitan area.

The Art and Design City (ADC) Ltd. was established in 1997 as broad partnership embracing from residents till the government all stakeholders interested in and relevant for the district's development. The ADC served as a multipurpose service company, which carried out simultaneously program and project management, local economic development, and was also responsible to organize provision of broadband connection for every apartment. The ADC's experts volunteered acting also as professional enablers ${ }^{1}$ facilitating the residents' self-organization.

\section{Institutional isomorphism through fundraising}

The Neighbourhood Association actively collaborated with professional enablers from ADC and with diverse stakeholders of the district's complex development program. In frame of an informal division of labour the Association gradually re-focused its activity on arrangement of funding for large, biennial happenings - so called "villa parties". In Arabianranta this event also aimed to promote the district's image as "art and design city" in order to stimulate its rising tourism².

The Neighbourhood Association, primarily the board focused its activity on fundraising in order to mobilize the significant amounts required to finance large biennial events. The Association gradually reduced its activity on mobilizing external financing, i.e. on fundraising carried out by the board members. Since its partners became various public and private donors and financial organizations the board had to fulfil multiple legal and financial obligations. The Association had to act on an organizational field, which in institutional dimension was characterised by dominance of zero-sum paradigm and by perception of resources as 'per definition' scarce. Exposed to powerful isomorphic institutional pressures (DiMaggio - Powell, 1983) the Association rapidly and imperceptibly was transformed into equilibrium seeking and hierarchical organization. "Today ...bureaucratization and other forms of organizational change occur as the result of processes that make organizations more similar without necessarily making them more efficient. Bureaucratization and other forms of homogenization emerge ...out of the structuration (Giddens, 1979) of organizational fields. ...highly structured organizational fields provide a context in which individual efforts to deal rationally with uncertainty and constraint often lead, in the aggregate, to homogeneity in structure, culture, and output" - as DiMaggio and Powell indicate (1983, p.147.).

The Association had to compete with many applicants for grants and subsidies and progressively lost its civil society organization feature and character. It followed instead dominance-seeking and bureaucratic attitude characteristic for market and public sector entities. By participating in fierce competition its organization was (re-) shaped into hierarchical structures and mechanisms facilitating to follow rules and expectations of various donors. The board members - by focusing on fundraising activity - had ever less time and readiness to deal with issues of daily life of residents or even to contact with members of the Association. The communication between the board and the members of Association became growingly formal or ceremonial (Meyer - Rowan, 1977), gradually slowed down and even halted. This created enhanced misfit between the Association's daily activities and the inhabitant's expectations therefore the residents stopped (attempts) to participate in the Association's daily work. Since the organization deprived itself from its most important and valuable resources, the board members became overloaded and with time they burned out.

\section{Initiative group launching self-organizing}

In 2007 a self-organizing group of residents created a new association to facilitate - the long delayed - establishment of a district community house. When the group by concentrating on practical steps contacted the city authorities the latter suggested liaising the Neighbourhood Association. Since the Association's board turned to be reluctant even to communicate, the group members started to criticise 
such 'powerholder' attitude. The initiative group urged to facilitate finding solution for problems, the residents' daily life instead of concentrating on ceremonial (Meyer - Rowan, 1977), growingly bureaucratic activities connected to fundraising and organization of biennial "large events". The group proposed to refocus the Association's activity on supporting the residents' self-organizing efforts aiming to improve life quality in the district and emphasized the necessity of enhanced transparency. This constellation is well characterized by the following interview excerpts:

\begin{abstract}
"A: (it was long planned to establish a communal house called) Kendebaika ...(since nothing happened)... we formed the. . Puhvila association to get it done ...to have...community spaces... that was...in 2007. ... the city answered to us that (since we) are not liable association (they aren't ready to) discuss this matter ...they said the Neighbourhood Association is...the legal representative for inhabitants of the area... we (should) discuss with the Neighbourhood Association..."(100-20-29-5:41-50) - explains the coordinator of the group reasons of their attempts to contact the Neighbourhood Association.
\end{abstract}

\section{"A: ...(the board of)... Neighbourhood Association in the beginning of 2008 ... was totally "dead" ... (they dealt only with the) huge villa parties in every second year.......but nothing else happened...(in between) ...they were exhausted because it is a huge work to organise those things...... the former board was burned out in last villa party... So we thought that we are not going to make ever this kind of (formal, ceremonial things)..."(100-20-29-5:464-478) - re- calls the coordinator of the new board the situation in Neighbourhood Association when re-election of its board took place.}

\section{"A: ...the (board members acted similarly as the) ...Art and Design City Helsinki (the local service company did). They wanted to keep the power and information... and then they...had to do eve- rything by themselves because nobody else would know or have power to do things. (But) I think that (exactly) that is the main thing...(mobilize others) ... that is why.... am telling ...that is the old way to do things..."(100-20-29-5:1137-1148) - elaborates on the mistaken approach of previous board the Asso- ciation's new coordinator.}

When the activist group published an alternative program on its website ${ }^{3}$ their proposals created growing resonance and the initiatives rapidly became popular topic of the residents' self-communication (Castells, 2009) ${ }^{4}$. The upcoming elections to the board of Neighbourhood Association (in 2008) generated elevated interest among residents. They vividly discussed potential directions of the Association's future activities and the district's development trajectory. The inhabitants appreciated and supported both the criticism and the proposals of the initiative group. Their major- ity was ready to contribute to voluntary cooperative efforts aiming to improve life quality in the district.

These cooperation-prone tendencies interplayed with changes in Neighbourhood Association. The group consistently implemented in practice the "unconditional primacy of transparency", their program's key principle. Their communicative interactions resonated with the resident's vivid self-communication by re-generating a cooperative atmosphere ${ }^{5}$. These alterations accelerated when participants of the initiative group became the Association's 'official members' despite the board's reluctance, attempts to delay and prevent their membership.

\section{"A: ... the Neighbourhood Association (previously) was... closed and (un-transparent)...small group... (which tried) keeping all (information) to them... It was for example very difficult to join to the Ne- ighbourhood Association, which should be open association. I sent many angry notes that you have to give me your bank account number that I could pay...the fee to be a...member. This is open orga- nization, you have to give it! ... it was so closed.... \\ Q: It was because they were afraid? Was it because they were tired? \\ A: They were totally tired"(100-20-29-5:1457-1475) - explains the new board's coordinator how and why the previous board tried to delay and prevent their "official membership".}

\section{Elections - takeover of professional enabling}

The board members' reluctance to cooperate with, and their failed attempts to exclude the (participants of the) initiative group from the Association became obvious for the residents. As a consequence all seven participants of the group were elected into the renewed board of Neighbourhood Association. A "coup d'état in the sandbox" took place - upon self-ironic and apt expression of the new coordinator. The rearrangement of the board's personal composition facilitated in multiple ways the spread of self-organizing interactions among residents. The new board focused on consequent implementation of the program, which they proposed previously as initiative group.

The new board carried out systematic orchestration, facilitation, and matchmaking. They took over professional enabling ${ }^{6}$ by catalysing spectacular increase in the residents' self-organizing activities. The rapid growth in the number of volunteers boosted also the (volume of) available resources. Such increase happened despite the fact that the renewed board agreed on the first meeting to stop applying for grants and subsidies with exception for financing trainings. The new board members decided to focus instead on mobilization of locally available resources what was proven by the practice.

"A: ....we started in beginning of 2008... We (decided)... that we do things by ourselves and (will) not wait to get funding or support...from the city ...the 
traditional way (is) to ask money and then if you got money ... start to do (something)... We started to do things ....we tried (and we realized) that we don't need money to most ... things. (We always asked:) What is the way that (with available) resources we can make ... it happen? That was very important line and we are doing it all the time now..."(100-20-29-5:1671-1677) describes the coordinator of the new board their decision to focus on resources available locally.

The members of the new board systematically contacted all local players convincing them to give information for the newspaper and web page of the district about their activities, plans, initiatives, successes and failures. They 'prayed transparency' and by focusing on its 'unconditional primacy' generated abundant information flow, which led to growing participation and many new initiatives. The regular information revealed many activities unfolding in the district of which the residents previously remained unaware. The two communal houses that the new board promoted to establish rapidly became overbooked by various activities? .

By learning about the residents' interest to better know each other ${ }^{8}$ the board systematically orchestrated local happenings. They supported proposals if and when the initiators were ready to actively participate in practical preparation of the events by providing free admission for everybody. This approach facilitated many "localized" happenings from regular recycling events till film festivals and dance evenings - often taking place right at the houses' doorsteps 9 . The board established and systematically broadened cooperation with the two neighbouring districts Toukola and Vanhakaupunki, their residents were always welcomed on any happenings in Arabianranta. The new board encouraged and supported local groups and organizations to establish and widen "external" contacts and collaboration. The vivid networking facilitated to access also significant amount of resources.

The board carried out systematically professional enabling, supported new initiatives, ensured matchmaking among potential partners. They enacted on multiple ways the residents' readiness and motivation to participate and contribute by catalysing growingly cooperative atmosphere. This approach allowed anticipating and handling challenges when hundreds of youngsters became teenagers by trying to establish their (young) adult personality. The signals from parents' associations and teachers allowed preparing and launching the district's "big project" aiming to maintain good relationships among youngsters and their parents ${ }^{10}$. The program successfully generated initiatives similar to special soccer trainings where kids and parents learned primarily to cooperate with each other with the help of professional coaches. The "second grandparents" movement of the Active Seniors Association aimed to establish trustful relationships with their 'second grandchildren'11. It helped to improve relations also among 'second' grandparents and 'real' parents by strengthening contacts among various generations and the residents in general.
The new board also paid special attention to identify and train future leaders of the local civil society and the Neighbourhood Association. Following a workshop discussing the district's future strategy volunteers started to systematically identify, check and describe local best practices. By working in small, two person teams they produced 'manuals', which enabled to establish a local knowledge repository and could be used also as learning material in frame of training programs for potential future leaders ${ }^{12}$. The board arranged systematic support for their 'future competitors'.

\section{Mainstreaming of mass self-organizing}

The broadening of self-organizing tendencies capitalized also on changes unfolding in the wider environment of Arabianranta. Initiatives related to open innovation tendencies and Living Laboratories became important components of the new development strategy of the Helsinki Metropolitan area and its local councils, as well as of the national information society strategies ${ }^{13}$. These tendencies generated enhanced attention to open innovation and promoted the citizen's self-organizing. Following the official 'roll out' of the pan-European network in 2006 Arabianranta started to act also as a Living Laboratory. The rapid decrease of previously generous budgetary financing of local innovative efforts in aftermath of the 2008 financial crisis accelerated the shift to self-organizing ${ }^{14}$.

\section{Model shift - self-empowerment through mass self-organizing}

These tendencies catalysed the residents' self-organizing mass collaboration and facilitated an overarching model shift in Arabianranta. For a decade the district was the domain of a Scandinavian variant, a welfare society related (externally) structured self-organization model, which Leadbeater (2006) described ${ }^{15}$. The professional enabling strengthening the local civil society, generating the emergence of its new capabilities catalysed the districts' successful development and brought about multidimensional changes. These tendencies were amplified when the Neighbourhood Association took over the systematic professional enabling of mass self-organizing.

\section{"A: ...l am enjoying what kind of things we can do with that Neighbourhood Association... ... it seems like some kind of Alice in Wonderland... that you can do (so many good things) with ...very small, limited power which we have... as representatives (of the) inhabitants of this area..."(100-20-29-5-550-554). "A: ...l can help people ...to come together and then they will go on. We don't even know about it. It's so wonderful and amazing"(100-20-29-5:748-754) - sums up the coordinator of the new board of As- sociation the positive effects and outcome of their efforts to act as professional enablers orchestrating the residents' self-organizing.}

The (re-)transformation of the Neighbourhood Association into active umbrella organization and the systematic 
professional enabling catalysed a rapid increase in the residents' self-organizing. The growing activity of the local civil society was simultaneously an important driver and a determining component of an emerging new development model. The self-organizing mass collaboration (Tapscott - Williams, 2006) swiftly and almost imperceptibly replaced the previously dominant (externally) structured self-organization (Leadbeater, 2006), which generated rather paternalistic, top-down tendencies. These changes were also accompanied with emotions in personal and organizational context:

"A: ... I think that the worst, the ugliest... situation was something like 2-3 years ago when ...many people...made ...their own association... I have found out ...that was the teen age time... It was difficult to me to understand that they are struggling because they want to make it as their own. Because this was my creation for me it was difficult to understand that I have to let it go. ... it is not any more my decision or my creation - it's something they are now creating by themselves. That was for me lesson to learn and hard to understand. OK this is the way. It goes and you have to let it go. You have to understand that it is normal. ...This is like teenage time ...(But still) I can't understand that. Can't go like...And it's terrible..."(100-20-3-5:1156-1163) - confesses the coordinator of volunteering professional enablers difficulties to say goodbye to structured self-organization and its often rather paternalist approaches.

"A: ... moderators (of the houses web-sites)... have discussed... What we can do with. . discussion board ...there is no... registration... (Seemingly) those meetings... have power to decide... (but officially nobody) would communicate...decisions... made by the moderators. ... the Art and design city Helsinki and Kari Halinen are that old way power keeper... limiting information... They are telling what...is good for $(A D C)$... I am totally different. . . personalyly... (ADC) is ... like a part of the city... (Upon their perception the inhabitants)... should not (interfere) because they are slowing down things... ... like Kari Halinen. We have done many things together. I think that $(A D C)$... is a very important company for this area. But there are ...different...methods to do things. And I think that ...we (the Neighbourhood Association) have a kind of huge place to fill up. To pick up...information and give people that...information. . .ask people to come to work groups, to involve (them) and give them voice in things which are concerning... their life ....that is why we have huge influence in this area because of that kind of hole...

Q: You are for participative democracy and Kari Halinen is more representative democracy framed person?

\begin{abstract}
A: Yeah!"(100-20-29-5:340-365) - explains the moderator of the new board the differences in approaches of the Neighbourhood Association and (the experts of the) $A D C$.
\end{abstract}

Through seamless shift in activities of Neighbourhood Association and the local civil society as a whole the mass self-organization quickly strengthened by catalysing quick emergence of a new pattern of local division of labour:

"A: (our relationship with $A D C$ ) goes with waves, because, we are also very demanding in certain things... we have also crises sometimes, but we still are talking. Now it comes closer...

\section{Q: So the relationships are not "flat", emotions play their roles...}

\section{A: ...we are...quite well filling different. . .holes toget- her. ...it's. . good combination... \\ Q: The different capacities can complement each other if you can properly combine them?}

\section{A: Yeah!"(100-20-29-5:602-614) - admits the effec- tiveness of an altered pattern of division of labour in the district the coordinator of the new board of Neighbourhood Association.}

\section{Quasi-quantification of the local civil society's (self-)empowerment}

The decade long structured self-organization created in Arabianranta outcomes, which one can describe through simple correlations among a few attributes. According to norms of the district development program one percent of expenses had to be spent on establishing pieces of art across the district ${ }^{16}$. The second, so called "fibre" rule prescribed to provide access to broadband for all residents starting from early 2000s. The provision of improving connectivity could have comparable expenses as (implementation of) the art rule.

These "initial investments" generated collaborative and trustful relationships among residents and their partners. Besides systematic extension and upgrading of cooperation with the two closest neighbourhoods in Helsinki the various players of local civil society intensely collaborated also with multiple interested partners from many countries around the world. I.e. the strong social capital enabled to extend the radius of trust beyond the district boundaries even "to a global reach".

There were circa 80 volunteers - from approximately 8000 residents - who systematically contributed to efforts aiming to catalyse self-organizing collaboration: i.e. $1 \%$ of residents belonged to the core, the most active enablers. These observations re-confirm the "Wikipedia-rule" (Jarvis, 2009, p. 60.) indicating that $1 \%$ of users are the most active contributors. Consequently a simple formula can 'describe' the program's outcome compared with characteristic components of targeted resourcing: 
$1 \%$ for art $+1 \%$ for "fibre" $->1 \%$ (rate of intense) participation

The pervasive presence of art and culture and the residents' enhanced connectivity interplayed with significant improvements in relationships. Upon expressive and striking formulation of the coordinator of the volunteering professional enablers this constellation created "plus ten percent tolerance" compared to other districts of Helsinki. The enhanced tolerance and readiness to cooperate contributed to a trajectory of local developments characterized also by obvious improvements in life quality. I.e. the interplay among enhanced (i) tolerance, (ii) participation and (iii) collaboration brought about (iv.) significant improvements in life quality. In other words, these tendencies facilitated to create abundant stock of social capital (Fukuyama, 1999) by catalysing highly cooperative atmosphere and relational dynamism - as 'return on investments' in art and connectivity catalysing increased participation. This constellation suggests another simple formula indicating:

$1 \%$ art $+1 \%$ "fibre" $+1 \%$ participation $->+10 \%$ tolerance $+(y) \%$ life quality improvement

These feed backing and catalytic tendencies promoted to accumulate social capital and value by generating mutually caring relationships, safe, trustful and collaborative atmosphere, by improving life quality and creating associational advantage in the district. This constellation became a widely known and appreciated "hallmark" of Arabianranta that was spread and amplified through "word of mouth" by creating also growing demand on apartments. I.e. the accumulation of social capital and value brought about an increase in economic, market value "instantiated" in growing real estate prices. What could be the ratio between "capitalizations" measured in social and market capital may be worth of further exploration. Anyway this constellation suggests another simple formula indicating:

$+10 \%$ tolerance $+(\mathrm{y}) \%$ life quality increase $->(\mathrm{X}) \%$ economic added value

\section{Professional enabling of empowering district-wide changes}

The overview of events and processes constitutive of multiple, sometimes controversial (self-) transformations of Neighbourhood Association facilitates to go beyond the quasi-quantitative correlations and identify underlying transformations through more in-depth qualitative analysis. The Neighbourhood Association successfully (re-) transformed itself into umbrella organization of local civil society, and also took over the professional enabling of mass self-organizing. The board catalysed in multiple ways the volunteers' interactions as well as their aggregation into profound shift in development trajectory of the district. This overarching, district-wide model shift unfolded through, was the aggregate - rather the process of aggregation - of self-empowering activities unfolding in various communities. The Neighbourhood Associa- tion in multiple ways facilitated the spread of bottom up and self-empowering self-organizing mass collaboration (Tapscott - Williams, 2006) by turning it into fundamental development pattern. The new model focused on horizontal mass self-organizing by overcoming paternalistic, top-down tendencies characteristic for the decade-long dominance of structured self-organization (Leadbeater, 2006). The local civil society through mass self-organizing transformed into an 'extended life sharing community' or a 'community of communities'. The robust cooperative dynamism facilitated increasing self-empowerment and due to its strong transformational character elevated into new dimension the development of the entire district.

\section{Discussion and Conclusions}

The transformational dynamism and its constitutive components described in connection with the Neighbourhood Association appear also in other communities of the explored cluster despite their apparent differences. The members of the Silvia koti and the Active Seniors communities planned and consciously established their daily life through cooperation and sharing. Although the Artist community was established as a loose group of co-tenants, it transformed almost imperceptibly into a genuine life-sharing community, a crucial source of mutual inspiration and the most important and valued dimension of the participants' daily life. The cooperative and mutually caring relationships among students, experts and volunteering 'users' played important role in successful co-creation of care TV and its services through growing involvement of the members of a true community. Among users of care TV services the personal contacts and common daily activities started in virtual space by gradually extending also into 'physical space'.

Without going this time into further details about other case-communities of the explored cluster one can ascertain that the volunteer cooperation among their members unfolds as genuine "life sharing" - upon the apt expression of an interviewee (100-20-4-5:238). The community members share most aspects of their daily life including values and principles, activities, tasks and resources. The volunteering participants perceive common achievements as personal, motivating success. Since their relationships are characterised by mutual care and empathy it facilitates their empowering individuation, the (re-) creation of their holistic personality and autonomous selves.

"...There is an important distinction between...- what could be called selfish individualism - and what is sometimes referred to as individuation ...Beck and Giddens... argue. Individuation is the freeing up of people from their traditional roles and deference to hierarchical authority, and their growing capacity to draw on wider pools of information and expertise and actively chose what sort of life they lead. Individuation is... as Beck points out... about the politicization of day-to-day life; the hard choices people face ...in crafting personal identities and choosing how to relate to issues such as race, gender, the environment, local culture, and diversity" - as Grenier (2006, p. 
124-125.) points out. The individuation may feedback with empowerment which “...(unfolds as a) multi-dimensional social process that helps people gain control over their own lives. It is a process that fosters power in people, for use in their own lives, their communities, and in their society, by acting on issues that they define as important... To create change we must change individually to enable us to become partners in solving the complex issues facing us. In collaborations based on mutual respect, diverse perspectives, and a developing vision, people work toward creative and realistic solutions. This synthesis of individual and collective change ...is our understanding of an empowerment process" - argue Page and Czuba (1999).

The community members wish to socialize - to participate for the sake of participation. In institutional context they follow the dual primacy of non-zero-sum approach and interdependence that interplays with horizontal power sharing enabling mutual empowerment. The volunteers carry out their contributions as passionate and sharing co-creation and compete in contributions to collective efforts. Their non-wage work generates significant use and social value by providing also exchange and economic value while their competition has participative character. The members of life-sharing communities perceive participation in collaborative efforts as the most valued, focal contribution and crucial resource. They often rely on special, "soft" resources similar to knowledge, information, creativity, which are non-depletable and non-rivalrous (Bollier, 2007, p. 28.) therefore multipliable and quasi-self-multiplying. These unique qualities enable to expand and upgrade also the collective resource base. While mobilizing locally available resources the volunteers frequently enact (often information-communication type) technologies enabling to gain quasi-global reach and generate local/global transformational dynamism.

The community members' collaboration and mutual care generates abundant social capital and extends the radius of trust by bringing about positive changes in their relationships also with "non-members". The vivid networking facilitates the cooperation's inclusive and un-fragmented character and generates its new dialectics. Consequently, the cluster of life sharing case-communities indicates the potential of civil society organizations to bring about changes, which can affect simultaneously the members, their relationships and organizations, as well as their broader environment. Their members are capable to initiate social innovations and affect in multiple ways their broader environment - carry out social agency in multiple ways.

The life-sharing case-communities demonstrate that the civil society organizations provide various, often significant transformational impacts in diverse dimensions, which are observable in empirical domain (Bhaskar, 1978; Tsoukas, 1989). These alterations frequently exhibit differing characteristics and diverse transformational impacts, i.e. at first sight may seem to 'emphasize' variations rather than similarities. However, the in depth analysis of the feed backing processes unfolding in real domain (Bhaskar, 1978; Tsoukas, 1989) proposes more coherent explanation. It points out that these phenomena are constituents of the civil society organizations' dynamism and create its transformational character and capability. The Table 2 summarises the components present in and characteristic for the case-communities' entire cluster, which are the drivers of the civil society organizations' transformational dynamism.

Table 2.

\section{Components of the civil society organizations' transformational dynamism}

\begin{tabular}{|l|l|}
\hline Personal context: & Empowerment \\
\hline & Individuation \\
\hline Relationships: & Institutional changes \\
\hline & Power relations \\
\hline Activities: & Work \\
\hline & Competition \\
\hline & Value creation \\
\hline & Resourcing \\
\hline $\begin{array}{l}\text { Alterations related to the commu- } \\
\text { nities' }\end{array}$ & Social agency \\
\hline self-transformation: & Networking self-upgrading \\
\hline & New dialectics of cooperation \\
\hline
\end{tabular}

\section{Proposal for further research}

In order to shed more light on causes and effects of the civil society organizations' transformational dynamism it is worth to consider that the interplay among its components unfolding in actual domain possesses non-linear character and their feed backs can form (self-reinforcing or self-extinguishing) loops (Veress, 2016). The analysis of their mutual effects must consider both "... immediate and distal causation"(Van de Ven and Poole, 2005:1382). I.e. it requires appreciating the importance of indirect causation and non-liner feedbacks as Forrester (1995) emphasizes by elaborating on "The counterintuitive behaviour of social systems". Consequently, a more fine-grained analysis of the civil society organizations' transformational dynamism probably can capitalise also on deployment of system dynamics.

\section{Notes}

1 The volunteer activity capitalized also on the director's personal motivation who was a resident of the district.

2 Around 500.000 visitors arrived yearly to Arabianranta who were mainly interested in art and design, and partly in the history - since this was the area where the ancient Helsinki was established in the XVI Century.

3 The coordinator of group acted also as e-Housekeeper, i.e. volunteer coordinator of the website of their house.

4 The "...mass self-communication...multiplies and diversifies the entry points in the communication process. This gives rise to unprecedented autonomy for communicative subjects to communicate at large. Yet, this potential for autonomy is shaped, controlled, and 
curtailed by the growing concentration and interlocking of corporate media and network operators around the world. Global multimedia business networks (including government-owned media) ...integrate the networks..., platforms... and channels of communication in their multilayered organizations, while setting up switches of connection to the networks of capital, politics, and cultural production..." (Castells, 2009,p. 135.)

5 The state-of-art local information-communication system providing broadband access served as catalyst.

6 They were critical regarding the way and effectiveness of the ADC experts' voluntary professional enabling.

7 The board successfully "launched" the "Kendebaika" community house "Q: ...you originally wanted to have access to the building... A: We should open on September 11"(100-20-29-5:417-420).

8 Since the residents wished to discuss issues related to security in the district the new board organized a workshop. The participants indicated the importance of better knowing each other that stimulated the board to orchestrate many small local events helping residents to become acquainted. (Since the residents also proposed changes in rules of traffic and in street lighting the board cooperated with responsible city council employees to arrange required changes in practice.)

9 The recycling events took place simultaneously on 18 various places in the district.

10 Many young families moved to Arabianranta starting from the early 2000 s and the average birth rate was also higher than in other parts of the capital.

11 Second grandparents attended the open soccer trainings and the dialogues with their second grandchildren had very favourable effects also on relationships among the teenagers and their ,real" parents...

12 The trainings for the future leaders they organized in cooperation with the two closest neighbourhoods and later together with the head-organization of the Helsinki neighbourhoods.

13 These trends became important constituents of efforts to overhaul large and complex regional and national innovation ecosystems by capitalizing on open innovation.

14 The ADC experts became responsible to transfer good practices from Arabianranta to the two new complex and thematic district development programs in Kalasatama and Jatkasaary by further increasing their work load letting little time for voluntary efforts to provide professional enabling.

15 In frame of structured self-organization - which Leadbeater (2006) describes by analysing the impressive success story of the Brazilian city, Curitiba - local authorities through systematic professional enabling generated and orchestrated the residents' self-organization. The enhanced participation of civil society and various players from the neighbourhood actively catalysed and contributed to local development.

16 On the facades and in the courts of buildings systematically established pieces of art and design and the inhabitants frequently identified their homes with them. The art became organic part of the residents' identity. Also majority of the tourists arrived to Arabianranta due to its image as art and design city.

\section{References}

Anheier, H. K. (2004): Civil Society: Measurement, Evaluation, Policy. Civicus World Alliance for Citizen Participation, Earthscan. London: Sterling VA

Bauwens, M. - Kostakis, V. (2017a): Solving the Crisis of Extractive Capitalism A new post-capitalist ecosystem of value creation. http://evonomics.com/post-capitalism-rewards-productive-michel-bauwens/

Bauwens, M. - Kostakis. V. (2017b): Cooperativism in the Digital Era, or How to Form a Global Counter-Economy. http://www.shareable.net/blog/cooperativismin-the-digital-era-or-how-to-form-a-global-countereconomy

Benkler, Y. (2011): The Penguin and the Leviathan The Triumph of Cooperation over Self-Interest. New York: Crown Business

Bhaskar, R. (1978): A realist theory of science. Hassocks: Harvester Press

Bollier, D. (2007): The growth of the Commons paradigm. In: Hess C. and Ostrom E. (eds.) (2007): Understanding knowledge as Commons From theory to practice. Cambridge MA: MIT Press, p. 27-41.
Bruyn, S. T. (2000): A Civil Economy Transforming the Market in the Twenty-First Century. Ann Arbor, MI: The University of Michigan Press

Castells, M. (2009): Communication power. Oxford: Oxford University Press

Chesbrough, H. (2003): Open Innovation: The new imperative for creating and profiting from technology. Boston, MA: Harvard Business School Press

Chesbrough, H. (2006): Open Innovation Researching a New Paradigm. Oxford: Oxford University Press

DiMaggio, P. J. - Powell, W.W. (1983): The Iron Cage Revisited: Institutional Isomorphism and Collective Rationality in Organizational Fields. American Sociological Review, 48, p. 147-160.

Eisenhardt, K. M. (1989): Building Theories from Case Study Research. Academy of Management Review, Vol. 14, No. 4 (Oct.), p. 532-550.

Eisenhardt, K.M. - Graebner, M. E. (2007) Theory building form cases: Opportunities and challenges. Academy of Management Journal. Vol. 50, No. 1, p. 25-32.

Enkel, E. - Gassman, O. - Chesbrough, H. (2009): Open R\&D and open innovation: exploring the phenomenon. R\&D Management. Volume 39, Issue 4, September, p. 311-316.

Feller, J. - Fitzgerald, B. - Hissam, S. A. - Lakhani, K. R. (eds.) (2005): Perspectives on Free and Open Source Software. Cambridge MA: MIT Press

Forrester, J. W. (1995): Counterintuitive Behavior of Social Systems. http://static.clexchange.org/ftp/documents/system-dynamics/SD1993-01CounterintuitiveBe.pdf

Fukuyama, F. (1999): Social Capital and Civil Society. In: IMF Conference on Second Generation Reforms. Available from:

http://www.imf.org/external/pubs/ft/seminar/1999/reforms/fukuyama.htm\#I (Accessed on 19 April 2016)

Grenier, P. (2006): Social Entrepreneurship: Agency in a Globalizing World. In: Nicholls, A. (ed.) (2006): Social Entrepreneurship: Agency in a Globalizing World. Oxford: Oxford University Press, p. 119-143.

Hess, C. - Ostrom, E. (eds.) (2007): Understanding knowledge as Commons From theory to practice. Cambridge MA: MIT Press

Hippel, E. von (1976): The dominant role of users in the scientific instrument innovation process. Research Policy, 5 (3), p. 212-239.

Hippel, E. von (1988): The Sources of Innovation. Oxford: Oxford University Press

Hippel, E. von (2005): Democratizing Innovation. Cambridge MA: The MIT Press

Jarvis, J. (2009): What Would Google Do? London: Collins Business

Koltko-Rivera, M. E. (2006): Rediscovering the Later Version of Maslow's Hierarchy of Needs: Self-Transcendence and Opportunities for Theory, Research, and Unification. Review of General Psychology, 10 (4), p. 302-317.

Leadbeater, C. (2006): The Socially Entrepreneurial City. In: Nicholls A. (ed.): Social Entrepreneurship - New 
Models of Sustainable Social Change. Oxford: Oxford University Press, p. 233-246.

Lee, S. - Nina M. - Weiss, M. (2003): Open Source as a Signalling Device - An Economic Analysis. http:// opensource.mit.edu/papers/leemoisaweiss.pdf

Maslow, A. H. (1943): A Theory of Human Motivation. The Psychological Review, 5 (4), p. 370-396.

Meyer, J. W. - Rowan B. (1977): Institutionalized Organizations: Formal structure as Myth and Ceremony. American Journal of Sociology, Vol. 83, No.2 (Sep.), p. 340-363.

Page, N. - Czuba, C. E. (1999): Empowerment: What is it? Journal of Extension, (Online) October, Volume 37 Number 5. http://www.joe.org/joe/1999october/ comm1.php

Raymond, E. S. (2001): The Cathedral \& The Bazaar Musings on Linux and Open Source By An Acidental Revolutionary. O'Reilly Media

Rifkin, J. (2004): The End of the Work, The decline of the global Labor Force and the Dawn of the Post-Market Era. London: Penguin

Rifkin, J. (2011): The Third Industrial Revolution: How Lateral Power Is Transforming Energy, the Economy, and the World. London: Palgrave Macmillan

Salamon, L. M. - Sokolowsky, W. S. - List, R. (2003): Global Civil Society An Overview - The Johns Hopkins Comparative Nonprofit Sector Project. Baltimore: The
Johns Hopkins University, Institute for Policy Studies, Center for Civil Society Studies

Stillman, L. J. H. (2006): Understandings of Technology in Community-Based Organisations: A Structurational Analysis. PhD Thesis. Faculty of Information Technology Monash University. Available from: http://webstylus.net/wp-content/uploads/2010/03/ Stillman-Thesis-Revised-Jan30.pdf

Tapscott, D. - Williams, A. D. (2006): Wikinomics: How Mass Collaboration Changes Everything. London: Portfolio Penguin Group

Taylor, R. (ed.) (2010): The Third Sector Research. London: Springer - International Society for Third Sector Research

Tsoukas, H. (1989): The validity of idiographic research explanations. Academy of Management Review, 14(4), p. 551-561.

Van de Ven, A. - Poole, M. S. (2005): Alternative Approaches for Studying Organizational Change. Organizational Studies, 26, p. 1377-1404.

Veress, J. (2016): Transformational Outcomes of Civil Society Organizations. Aalto University. http://urn.fi/ URN:ISBN:978-952-60-7085-8

Yin, R. (1981): The case study crisis: Some answers. Administrative Science Quarterly, 26, p. 58-65.

Yin, $R$. (1994): Case study research: Design and methods. Newbury Park, CA: Sage 